\title{
Study of technological parameters and material consumption of two-layer knitted fabric
}

\author{
Gulom Allaniyazov ${ }^{1 *}$, Kurbonali Kholikov², Gulfiya Gulyaeva ${ }^{3}$, Nuriddin Musaev $^{3}$, and \\ Mirabzal Mukimov ${ }^{3}$ \\ ${ }^{1}$ Nukus State University, 230105 Nukus, Uzbekistan \\ ${ }^{2}$ Namangan Engineering Technological Institute, 190110 Namangan, Uzbekistan \\ ${ }^{3}$ Tashkent Institute of Textile and Light Industry, 100100 Tashkent, Uzbekistan
}

\begin{abstract}
This article presents the results of a study of technological parameters and material consumption of new structures of two-layer knitted fabric. To study the technological parameters of new variants of two-layer knitted fabric on a Long Xing 252 SC flat-fanged machine, five variants of two-layer knitted fabric were developed, which differed from each other in the weave structure.
\end{abstract}

\section{Introduction}

The loop structure of knitted fabric is characterized by the fact that the filling of a unit of its area with threads is less than that of woven fabrics. As a result of this, knitted fabrics have a higher bulk (knitted fabric density $0.2-0.3 \mathrm{~g} / \mathrm{cm}^{3}$, fabric density $1.1-1.3 \mathrm{~g} / \mathrm{cm}^{3}$ ) [1]. At the same time, the consumption of threads in the production of a unit of area is dense by the knitted method is less than by the weaving one. This is one of the defining criteria for the advantages of the economics of the knitted production method [2].

The decrease in the material consumption of knitted products, in comparison with fabrics, is due not only to the structure of the material. Raising the class of knitting machines and the use of threads of low linear density is a generally direction of reducing the consumption of raw materials. At present, cross-knitting machines of 28-32 class are widely introduced; models of machines of 42 class have been created [3].

For example, when switching from knitting fabric on machines $18 \mathrm{cl}$. to knitting it on machines $22 \mathrm{cl}$. surface density is reduced by $10-15 \%$. Raising the class, as a rule, necessitates the use of threads of lower linear density (otherwise, the surface density of the material increases) [4].

A further reduction in the consumption of raw materials can be achieved due to the inclusion of patterned stitch elements in the knitted fabric structure. Knitted fabric of patterned stitch is formed on the basis of the main or derivatives by introducing additional elements into them (tuck sketches, broaches, additional threads) or by changing the production processes, allowing obtaining knitted fabric with new properties [5].

\footnotetext{
*Corresponding author: g.allaniyazov@yandex.com
} 
The location of the loops in knitted fabric and the ties between the loops can be very diverse and are determined by the stitch of the knitted fabric [5]. The thread that forms the loop is in force interaction with the adjacent loops, due to which a certain shape and size of the loops, as well as the entire jersey, is preserved.

Knitted fabric in an equilibrium state does not tend to change in size and has a fairly high stability. However, after finishing the knitted fabric, its loop structure can come to a non-equilibrium state, which, in terms of the geometric parameters of the loops, will differ significantly from the equilibrium state. The stability of a fixed (non-equilibrium from the point of view of the force interaction of the threads) knitted fabric largely depends on the properties of the fiber (thermoplasticity) and the means of fixation used [6, 7].

Along with the threads used for the manufacture of knitted fabric, stitch type is its most important characteristic and determines the properties of knitted fabric: extensibility, dissolving, surface density, thickness, dimensional stability, etc. Knitted fabric is characterized by a wide variety of stitch. By using different stitch, you can get knitted fabric with different properties, patterned or structured effects [8].

Currently, in the production of knitted fabrics and products, two-layer stitch are often used, which allow you to obtain all kinds of patterned effects and modify the structure and properties of knitted fabric. The knitted fabric of two-layer stitch is formed by a combination of main, derivative and patterned stitch. Such combinations can have an unlimited number of variants, which depend on the purpose of the knitted fabric, the required properties and the patterned effect to be obtained [9].

Double layer knitted fabric can be obtained on all kinds of double knitting machines. Especially widespread use is found in double-layer knitted fabric from fang, purl and interlock machines.

The most rational way to improve the quality of knitted products is to use two-layer knitted fabrics, because in two-layer knitted fabric, you can combine various types of stitch, based on the set of properties that you want to give to the fabric being produced.

\section{Materials and Methods}

To study the technological parameters of new variants of two-layer knitted fabric on a Long Xing 252 SC flat knitting machine, five variants of two-layer knitted fabric were developed, which differed from each other in the stitch structure.

The raw material used cotton yarn of linear density 30 tex $x 2$ for one side of the twolayer knitted fabric and polyacrylonitrile (PAN) yarn of linear density 32 tex x 2 for the other side and for the weft thread.

When designing the threading of any new knitted fabric or knitted products, usually operate with such parameters as the loop step A, the height of the loop row B, the length of the thread in the loop $l$. The surface density of jersey and its properties depend on them. Knowing the dependence of properties on the parameters of the knitted fabric, you can choose the optimal machine threading.

The two-layer knitted fabric of weft and warp-knitted stitch, various in structure, can satisfy the most varied requirements in relation to the parameters and indicators of properties that are presented in the practice of manufacturing clothing and technical products.

\section{Results and Discussion}

The parameters of any knitted fabric are influenced by the properties of raw materials, the type of stitch and finishing. Fig. 1 highlights a graphical record of the production of twolayer knitted fabric. 


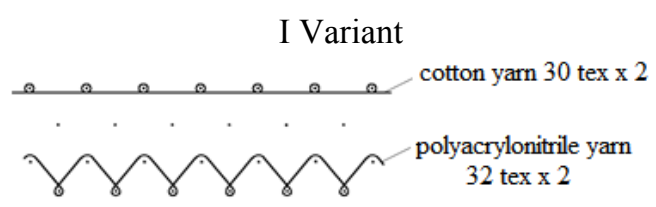

III Variant

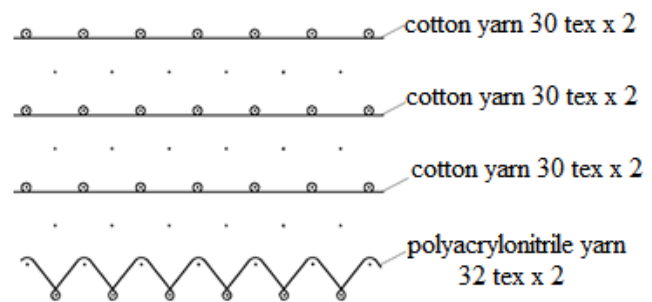

II Variant

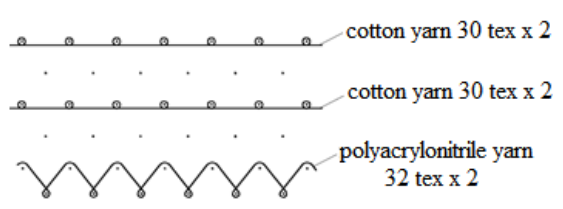

IV Variant

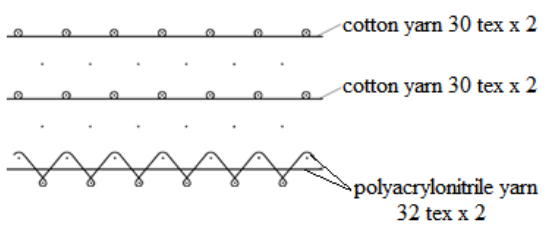

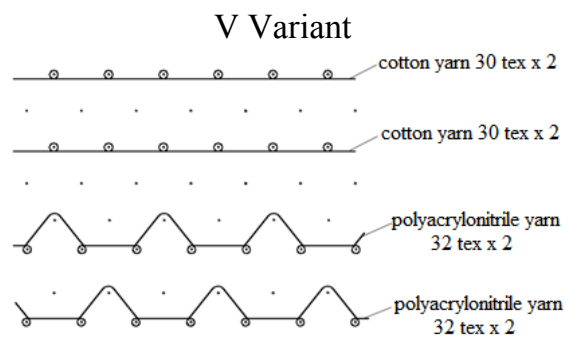

Fig. 1. Graphical recording of the production of two-layer knitted fabric

For the basic variant for comparing the parameters and properties of new variants for two-layer knitted fabric, variant I was adopted, developed on the basis of weaving of semifangs, where the press method of joining with warp threads is used to join the layers of knitted fabric. The technological parameters of two-layer knitted fabric were determined according to the standard method $[3,4]$ in the "CentexUz" laboratory at TITLP, the results are given in Table 1.

Two-layer knitted fabric consists of two identical or two different single fabrics, one of them may have different parameters from the other. This determines the interaction of the layers. One layer, when connected to another, can change its initial parameters, and the other, in turn, change the parameters of the first. Therefore, the density and length of the threads in the loops of the layers of two-layer knitted fabric cannot be determined using the corresponding formulas for single stitch. In addition, these parameters depend on the type and method of connection [10-14].

The technological parameters of knitted fabric can be determined in three ways:

1. According to standards. This method can be used when it is not required to determine the parameters of knitted fabric by calculation (for example, when calculating the weight of finishing parts, liners, erasers, etc.) or when the technological parameters of knitted fabric, established according to existing calculation formulas, have significant deviations from the actual indicators (for example, when determining the parameters of knitted fabrics of new stitch or made from new types of raw materials). But standards do not cover all types of threading and stitches; 
2. Experimentally by threading. This method is most often used in research projects related to the development of new knitted fabric stitch. This method requires the availability of the necessary equipment, and raw materials;

3. Calculation method. This method can be applied in all design cases. The sequence of calculating technological parameters depends on the method adopted for calculating the loop length 1 [9].

Table 1. Technological parameters of two-layer weft knitted fabric

\begin{tabular}{|c|c|c|c|c|c|c|}
\hline \multirow{2}{*}{\multicolumn{2}{|c|}{ Indicators }} & \multicolumn{5}{|c|}{ Variants } \\
\hline & & \multirow{2}{*}{$\begin{array}{c}\text { I } \\
64,4\end{array}$} & \multirow{2}{*}{$\begin{array}{l}\text { II } \\
49\end{array}$} & \multirow{2}{*}{$\begin{array}{c}\text { III } \\
39\end{array}$} & \multirow{2}{*}{$\begin{array}{l}\text { IV } \\
52\end{array}$} & \multirow{2}{*}{$\begin{array}{l}\mathrm{V} \\
58\end{array}$} \\
\hline The content of threads in & Face layer & & & & & \\
\hline the fabric, $\%$ & Back layer & 35,6 & 51 & 61 & 48 & 42 \\
\hline \multirow{2}{*}{ Loop width A, mm } & Face layer & 2,3 & 2,2 & 2,2 & 2,3 & 2,2 \\
\hline & Back layer & 2,3 & 2,2 & 2,2 & 2,3 & 2,2 \\
\hline \multirow{2}{*}{ Hight of loop row $\mathrm{B}, \mathrm{mm}$} & Face layer & 1,42 & 2,38 & 3,13 & 2,5 & 2,38 \\
\hline & Back layer & 1,35 & 1,25 & 1,19 & 1,28 & 1,25 \\
\hline \multirow{2}{*}{$\begin{array}{l}\text { Horizontally density } \mathrm{P}_{\mathrm{h}} \\
\text { loops in a } 50 \mathrm{~mm} \text { by the } \\
\text { course }\end{array}$} & Face layer & 22 & 23 & 23 & 22 & 23 \\
\hline & Back layer & 22 & 23 & 23 & 22 & 23 \\
\hline \multirow{2}{*}{$\begin{array}{l}\text { Vertically density } \mathrm{P}_{\mathrm{v}} \text {, loops } \\
\text { in a } 50 \mathrm{~mm} \text { by the wale }\end{array}$} & Face layer & 35 & 21 & 16 & 20 & 21 \\
\hline & Back layer & 37 & 40 & 42 & 39 & 40 \\
\hline \multirow{2}{*}{$\begin{array}{l}\text { Length of thread in the loop } \\
\qquad l, \mathrm{~mm}\end{array}$} & Face layer & 16,54 & 16,46 & 16,18 & 16,36 & 10,8 \\
\hline & Back layer & 6,95 & 6,92 & 6,56 & 6,88 & 6,7 \\
\hline \multicolumn{2}{|c|}{ Surface density $M_{S}, g / m^{2}$} & 508 & 370,7 & 374,4 & 389,4 & 459,3 \\
\hline \multicolumn{2}{|c|}{ Thickness $\mathrm{T}, \mathrm{mm}$} & 1,8 & 1,4 & 1,5 & 2,1 & 1,95 \\
\hline \multicolumn{2}{|c|}{ Bulk density $\delta, \mathrm{mg} / \mathrm{cm}^{3}$} & 282,2 & 264,3 & 249,6 & 185,4 & 235,5 \\
\hline \multicolumn{2}{|c|}{ Absolutely bulk lightness $\Delta \delta, \mathrm{mg} / \mathrm{cm}^{3}$} & - & 17,9 & 32,6 & 96,8 & 46,7 \\
\hline \multicolumn{2}{|c|}{ Relative bulk lightness, $\theta, \%$} & - & 7 & 12 & 34 & 17 \\
\hline
\end{tabular}

The indicators characterizing the structure of knitted fabrics are: surface and bulk density, density (number of loops per unit length) in the longitudinal and transverse directions, thread length in the loop, skew angle of loop rows and loop stitches, knitted fabric thickness.

An analysis of the results of studies carried out by many scientists showed that a decrease in the surface density of knitted fabric within certain limits leads to a decrease in the consumption of raw materials and is less dangerous for its strength properties, since the absolute value of the strength of knitted fabrics is high, and during operation, the products are subjected to loads not exceeding $20 \%$ of breaking loads.

The criterion for material consumption is traditionally considered the surface density of the fabrics. A decrease in the surface density of knitted fabric entails a change in the operational and hygienic characteristics. Therefore, an indicator is introduced, which simultaneously characterizes both the material consumption of the fabrics and the quality indicator. Such an indicator is an indicator of the lightness of the structure of knitted fabric, in which, along with the surface density, its thickness is also taken into account $[8,9]$. 
The results of the study showed that the bulk density of the recommended samples of two-layer knitted fabrics is less in comparison with the basic stitch (variant I) (Table 1 and Fig. 1).

If the areal density of the base stitch is $\mathrm{Ms}=508 \mathrm{~g} / \mathrm{m}^{2}$ and the thickness is $\mathrm{T}=1.8 \mathrm{~mm}$, its bulk density is $\delta=282.2 \mathrm{mg} / \mathrm{cm}^{3}$.

In this case, the indicators of the absolute volumetric relief of the fabrics in comparison with the base stitch will be as follows:

$$
\begin{aligned}
\Delta \delta & =\delta_{\sigma}-\delta=282,2-264,3=17,9 \mathrm{mg} / \mathrm{cm}^{3} \quad \text { (II var.) } \\
\Delta \delta & =\delta_{\sigma}-\delta=282,2-249,6=32,6 \mathrm{mg} / \mathrm{cm}^{3} \quad \text { (III var.) } \\
\Delta \delta & =\delta_{\sigma}-\delta=282,2-185,4=96,8 \mathrm{mg} / \mathrm{sm}^{3} \text { (IV var.) } \\
\Delta \delta & =\delta_{\sigma}-\delta=282,2-235,5=46,7 \mathrm{mg} / \mathrm{cm}^{3} \text { (V var.) }
\end{aligned}
$$

where, $\Delta \delta$ - volumetric ease, $\mathrm{mg} / \mathrm{cm}^{3} ; \Delta \mathrm{b}$ - bulk density of the base variant, $\mathrm{mg} / \mathrm{cm}^{3}$; and, $\delta$ - bulk density of the investigated variant $\mathrm{mg} / \mathrm{cm}^{3}$.

The relative lightening of the manufactured samples of two-layer knitted fabric is as follows:

$$
\begin{gathered}
\theta=\left(1-\frac{\delta}{\delta_{\sigma}}\right) \cdot 100 \%=\left(1-\frac{264,3}{282,2}\right) \cdot 100 \%=7 \% \quad(\mathrm{II} \text { var. }) \\
\left.\theta=\left(1-\frac{\delta}{\delta_{\sigma}}\right) \cdot 100 \%=\left(1-\frac{249,6}{282,2}\right) \cdot 100 \%=12 \% \quad \text { (III var. }\right) \\
\left.\theta=\left(1-\frac{\delta}{\delta_{\sigma}}\right) \cdot 100 \%=\left(1-\frac{185,4}{282,2}\right) \cdot 100 \%=34 \% \quad \text { (IV var. }\right) \\
\left.\theta=\left(1-\frac{\delta}{\delta_{\sigma}}\right) \cdot 100 \%=\left(1-\frac{235,5}{282,2}\right) \cdot 100 \%=17 \% \quad \text { (V var. }\right)
\end{gathered}
$$

As can be seen from Fig. 2, the smallest consumption of raw materials in the production of two-layer knitted fabric is required for the fourth version of knitted fabric, i.e. the bulk density of knitted fabric is the lowest compared to other variants. The bulk density of knitted fabric varies in a very wide range, depending on the type and size of the threads used their density, class and type of machines and stitch.

Changes in the structure of the seamy layer of two-layer knitted fabric, where in the repeat of fabric instead of one plane row (variant I), three plane loop rows are formed (variant III) have a significant effect on the parameters and, first of all, on the surface density and thickness of the knitted fabric (Fig. 3).

A decrease in the consumption of raw materials in the production of II, III variants of two-layer knitted fabric, compared to the basic stitch (I variant), is achieved by increasing the number of plane stitch rows of the repeat on the seamy side of the fabric. In the IV variant of two-layer knitted fabric, a decrease in the consumption of raw materials is achieved by increasing the number of plane rows in the stitch rapport and the inclusion of a weft thread in the knitted fabric structure. 


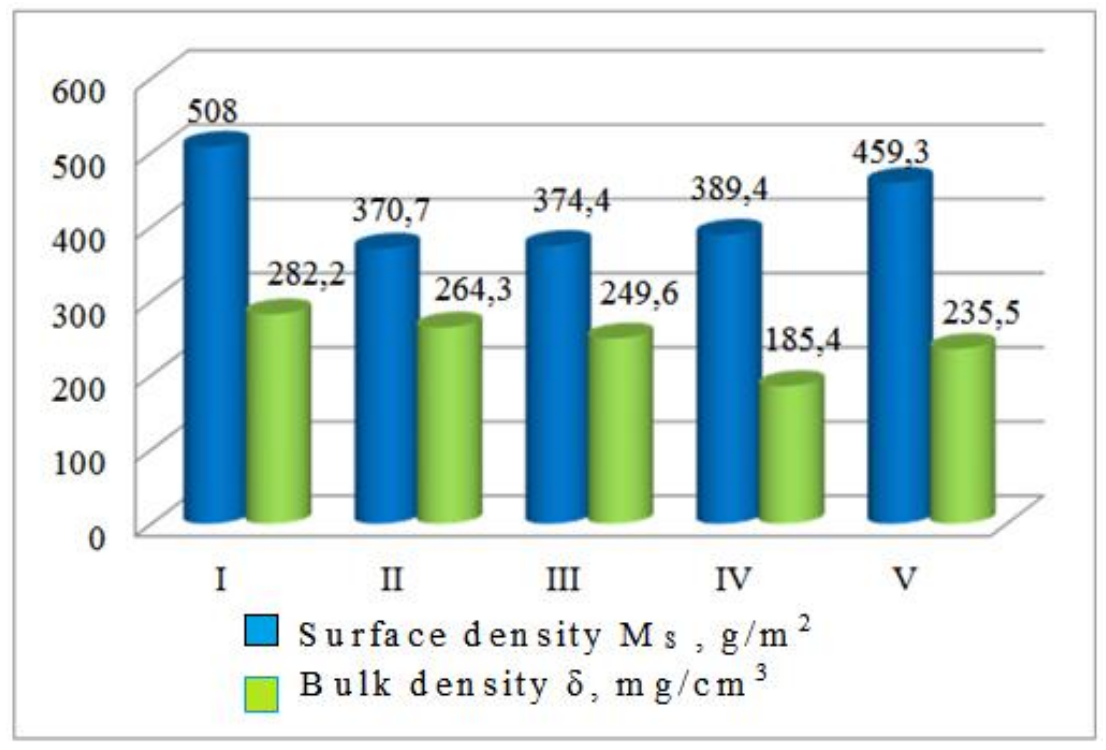

Fig. 2. Histogram of changes in surface and bulk density of two-layer knitted fabric

Thanks to the proposed structure of knitted fabric, it becomes possible to increase the volume and thickness of the knitted fabric and reduce the extensibility in width, and therefore, to solve the problem posed - to create a two-layer knitted fabric with increased dimensional stability. In addition, the use of this solution will reduce irreversible deformations of finished products, and therefore, expand the application area and assortment of knitted fabric.

When the $\mathrm{V}$ variant of a two-layer knitted fabric causes a decrease in the bulk density of the knitted fabric is achieved by changing the methods of joining the layers of the twolayer knitted fabric.

\section{$\mathrm{I}=1.8 \mathrm{~mm}$}

$$
\mathrm{II}=1.4 \mathrm{~mm}
$$

\section{$\mathrm{III}=1.5 \mathrm{~mm}$}

\section{IV $=2.1 \mathrm{~mm}$}

\section{$\mathrm{V}=1.95 \mathrm{~mm}$}

Fig. 3. Thickness of two-layer knitted fabric 


\section{Conclusions}

According to the results of the study of the technological parameters of two-layer knitted fabrics, presented in the table, it can be noted that a comparison of knitted fabrics with each other in terms of surface density (Fig. 1) showed that the second version of two-layer knitted fabric has the lowest surface density, and a comparison of samples in terms of bulk density showed that the lowest bulk density is possessed by the IV variant of two-layer knitted fabric, because the thickness of the IV variant of the knitted fabric is greater than that of the other variants.

In conclusion, it can be noted that by changing the structure of the layers of two-layer knitted fabric, it is possible to obtain knitted fabric with specified properties and reduced material consumption. The developed two-layer knitted fabrics can be successfully used for the manufacture of upper and children's assortment.

\section{References}

1. I. Tsitovich, Technological assurance of the quality and efficiency of knitting processes in cross-knitted jersey, 240 (Legprombytizdat Press, Moscow, 1992)

2. I. Shalov, Combined knit stitch, 23 (MTI Press, Moscow, 1971)

3. Z. Torkunova, Light Industry 7, 19 (1995)

4. Yu. Shustov, Fundamentals of Textile Materials Science 18, 189-201 (2007)

5. I. Shalov, Light and food industry 198(21), 21 (1994)

6. I. Shalov, A. Dalidovich, L. Kudryavin, Knitted fabric technology, 375 (Legprombytizdat Press, Moscow, 1986)

7. A. Dalidovich, Light Industry 22, 15 (1999)

8. K. Yunusov, N. Khankhadzhaeva, M. Mukimov, "Infotekstil-2005": Implementation of information communication technologies in the textile and light industry. Collection of articles rep. Scientific and practical Conf., 65-66 (2006)

9. N. Hanhadjaeva, Safety and quality of food and consumer goods: Conference proceedings, 126-128 (2009)

10. Patent No. 9405770 (France), MPK6 D 04 B 7/04. A method for producing a two-layer knitted fabric. Thevenet Bruno. Protecma (S.a.2.1) Application No. 2719606. Appl. 05.05.1994. Publ. 10.11.1995

11. Patent No. 6089052 (USA), IPC7 D 04 B 21/00. Riegger Stephen No. 09/136150. Appl. 18.08.1998. Publ. 07/18/1996. NPK 66/195

12. Patent No. 6194332 (USA), IPC7 B 32 B 15/00 D 04 B 1/16. Malden Mills Ind, Inc. Rock Moshe, Lumb Douglas, Lie William K. No. 09/219920. Appl. 12/23/1998. Publ. February 27, 2001. NPK 442/312

13. Patent No. 2288980 (Russia), IPC D 04 B 1/00. Two-layer jersey. G.A. Bronze, V.S. Kulikov. Appl. April 15, 2005. Publ. 10.12.2006 